\title{
Gender Differences in Factors Associated with Clinically Meaningful Weight Loss among Adults Who Were Overweight or Obese: A Population-Based Cohort Study
}

\author{
Ji-Bin Lia,b Zhi-Yu Qiub, c Zhen Liu ${ }^{d}$ Qian Zhou ${ }^{\text {e }}$ Li-Fen Feng ${ }^{f}$ \\ Jun-Dong Li ${ }^{b, g} \quad$ Xi Zhang ${ }^{h}$
}

${ }^{a}$ Department of Clinical Research, Sun Yat-sen University Cancer Center, Guangzhou, PR China; ${ }^{b}$ State Key Laboratory of Oncology in South China, Collaborative Innovation Center for Cancer Medicine, Guangzhou, PR China; 'Department of Liver Surgery, Sun Yat-sen University Cancer Center, Guangzhou, PR China; ${ }^{\mathrm{d}}$ Department

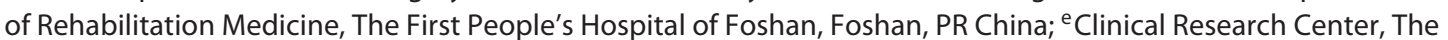
First Affiliated Hospital, Sun Yat-Sen University, Guangzhou, PR China; ${ }^{\mathrm{f}}$ Department of Statistics, Government Affairs Service Center of Health Commission of Guangdong Province, Guangzhou, PR China; ${ }^{9}$ Department of Gynecologic Oncology, Sun Yat-sen University Cancer Center, Guangzhou, PR China; ${ }^{h}$ Clinical Research Unit, Xin Hua Hospital, Shanghai Jiao Tong University School of Medicine, Shanghai, PR China

\section{Keywords}

Predictors · Clinically meaningful weight loss · Gender difference $\cdot$ Adults

\begin{abstract}
Objectives: The impact of heterogeneity on gender difference for achieving clinically meaningful weight loss ( $\mathrm{cmWL}$ ) remains unclear. Here, we explored the potential gender differences in factors associated with cmWL. Methods: A total of 60,668 participants with body mass index (BMI) $\geq 25 \mathrm{~kg} /$ $\mathrm{m}^{2}$ at study entry and available BMI values at follow-up were included in this study. cmWL was defined as a weight loss of $\geq 5 \%$ from the study entry to follow-up. The associations of social-demographic factors, personal history of chronic diseases, lifestyle behaviors, and history of BMI with $\mathrm{cmWL}$ were evaluated using logistic regression models. Results: During a median follow-up of 9.13 years, $26.6 \%$ of the participants had a cmWL (30.8\% for females vs. $23.1 \%$ in males; $p<0.001$ ). Participants with older age, obesity at study entry, being more physical activity compared to 10 years ago, being re-
\end{abstract}

karger@karger.com www.karger.com/ofa

Karger $\stackrel{\text { ' }}{5}$

BOPEN ACCESS
(C) 2020 The Author(s)

Published by S. Karger AG, Basel

This article is licensed under the Creative Commons AttributionNonCommercial-NoDerivatives 4.0 International License (CC BYNC-ND) (http://www.karger.com/Services/OpenAccessLicense). Usage and distribution for commercial purposes as well as any distribution of modified material requires written permission. lapsed smokers or consistent current smokers, having a history of chronic diseases (i.e., diabetes, osteoporosis, and stroke), cancer diagnosis during the study period, and more than 10-year follow-up were more likely to achieve $\mathrm{cmWL}$ in both males and females (all $p<0.05$ ). The new smoking quitters and participants with less active in physical activity compared to 10 years ago were less likely to achieve $\mathrm{cmWL}$ in both males and females (all $p<0.05$ ). Specifically, males with a history of emphysema were more likely to reach $\mathrm{cmWL}$, and for females, those being overweight at 20 years old and current drinkers were more likely to reach $\mathrm{cmWL}(p<0.05)$. Sensitivity analyses demonstrated similar results. Conclusion: Age, BMI status, physical activity, smoking status, family income, and health status were independent factors in males and females for weight management. However, further well-designed prospective studies are warranted to confirm our findings.

(c) 2020 The Author(s)

Published by S. Karger AG, Basel

Xi Zhang

Clinical Research Unit, Xin Hua Hospital

Shanghai Jiao Tong University School of Medicine

1665 Kongjiang Road, Kejiao Building 233B, Shanghai 200092 (PR China)

zhangxi@xinhuamed.com.cn

Jun-Dong Li

Department of Gynecologic Oncology

Sun Yat-sen University Cancer Center

Dong Feng East Road 651, Guangzhou 510060 (PR China)

lijd@ sysucc.org.cn 


\section{Introduction}

Excess body weight (i.e., overweight and obesity) is a prominent global health issue. Its prevalence in adults has increased from $21 \%$ in men and $24 \%$ in women to almost $40 \%$ in both genders, in the past 4 decades [1]. Excess body weight increases the risk of chronic diseases, such as cardiovascular diseases [2], diabetes mellitus [3], musculoskeletal disorders [4], and cancers [5, 6]. Clinically meaningful weight loss $(\mathrm{cmWL})$, defined as more than $5 \%$ weight loss from initial body weight, has been associated with significant health benefits among adults, such as a decreased risk of chronic health conditions (e.g., diabetes, hypertension, cancers) and mortality [7-9]. Moreover, intentional weight loss could reduce obesity-related oxidative stress and promote self-well-being [10, 11]. However, successful weight loss along with its long-term maintenance is challenging. Around $63 \%$ of adults with obesity in the US expressed a strong desirability to control their body weight, while only $40 \%$ of them successfully reached cmWL [12]. In exercise-based interventional studies aiming to induce weight loss, the observed mean weight loss was modest and sometimes far less than the investigated individuals' expectations [13]. The potential benefits of weight loss on well-being highlight the necessity to investigate factors associated with the successful $\mathrm{cmWL}$ among the general population, and such information would be useful for designing effective intervention programs for body weight management.

A variety of potential factors were found to be associated with weight loss, such as demographic factors (e.g., older age, marital status, ethnicity), severe obesity, healthy lifestyle (e.g., reduced energy intake, moderateto-vigorous intensity physical activity), and medical interventions (e.g., surgery, pharmacotherapy, behavioral intervention) [14-21]. Several studies have also reported that gender differences may impact weight control. A community survey among older adults with obesity from the US and UK evaluated the demographic predictors of $\mathrm{cmWL}$ and found that women had generally better weight control than men [16]. In contrast, a meta-analysis of 49 randomized controlled trials found that men might lose slightly more weight than women in both diet and diet plus exercise interventions [22]. This inconsistency regarding gender difference in weight control might be partially attributed to the differences of the study sites (i.e., community vs. clinical site), study duration, baseline body weight, enrolled sample size, and types of interventions. Compared with clinical studies, community-based cohort studies could reveal more epi- demiological implications regarding body weight management for the general population.

The gender difference in weight control is definitely observed. Nevertheless, heterogeneity resource of gender difference related to weight control was still unclear. Only a few studies, some examined weight loss only in men or women and some in both genders, have reported some gender-specific predictors, such as workday sitting time and marital status for men, leisure-time physical activity and stress for women, to be associated with weight loss [23-28]. However, few studies compared 2 gender groups to explore the potential difference in predictors associated with weight loss.

In this study, using a large-scale prospective cohort from the Prostate, Lung, Colorectal and Ovarian (PLCO) program, we systematically explored the gender differences in potential predictors associated with $\mathrm{cmWL}$ among adults who were overweight or obese, including social-demographic factors, personal history of chronic diseases, lifestyle behaviors and their changes during the study period, and the history of body mass index (BMI).

\section{Methods}

\section{Study Design and Participants}

The participants were a sub-sample of the PLCO cancer screening trial program. The study was designed as previous reported [29]. Briefly, a total of 154,879 eligible participants, aged from 55 to 74 years from ten centers in the US, were enrolled from 1993 to 2001. Recruitment at all centers ended in 2001. Participants were annually followed up for incidence of cancers and cause-specific mortality until December 31, 2009. All participants self-completed a questionnaire at study entry, and a subsequent follow-up survey was introduced to update the baseline information in 2006. This study was a secondary analysis for the data from the PLCO program, and the trial was approved by the Institutional Review Board of the National Cancer Institute and the participating centers.

In this study, eligible participants were those with: (1) BMI $\geq 25$ $\mathrm{kg} / \mathrm{m}^{2}$ at study entry; (2) no personal history of cancers before study entry; and (3) available BMI values at follow-up. Consequently, a total of 60,668 participants were included in this study.

\section{Potential Predictors}

Social-Demographic Factors. Participants' age, race/ethnicity, education level, annual family income, marital status, occupational status, and family history of cancer in the first relative degree were self-reported according to the standard questionnaire at study entry.

Personal History of Chronic Diseases. Information on a personal history of arthritis, diabetes, emphysema, heart attack, hypertension, osteoporosis, and stroke were self-reported using the questionnaire. Additionally, the incidence of cancer after study entry was ascertained by proper diagnostic evaluation and recorded through an annually update questionnaire, telephone calls, cancer registries, medical records, and/or death certificate [29]. 
Table 1. Sample characteristics of participants stratified by gender

\begin{tabular}{|c|c|c|c|}
\hline Characteristics & $\begin{array}{l}\text { Total } \\
(n=60,668)\end{array}$ & $\begin{array}{l}\text { Males } \\
(n=33,026)\end{array}$ & $\begin{array}{l}\text { Females } \\
(n=27,642)\end{array}$ \\
\hline \multicolumn{4}{|l|}{ Age at randomization } \\
\hline$\leq 59$ years & $22,507(37.1)$ & $12,040(36.5)$ & $10,467(37.8)$ \\
\hline 60-64 years & $19,737(32.5)$ & $11,040(33.4)$ & $8,697(31.5)$ \\
\hline $65-69$ years & $12,547(20.7)$ & $6,935(21.0)$ & $5,612(20.3)$ \\
\hline$\geq 70$ years & $5,877(9.7)$ & $3,011(9.1)$ & $2,866(10.4)$ \\
\hline \multicolumn{4}{|l|}{ Race/ethnicity } \\
\hline Non-Hispanic Whites & $55,626(91.7)$ & $30,397(92.0)$ & $25,229(91.3)$ \\
\hline Non-Hispanic Blacks & $2,233(3.7)$ & $848(2.6)$ & $1,385(5.0)$ \\
\hline Others & $2,809(4.6)$ & $1,781(5.4)$ & $1,028(3.7)$ \\
\hline \multicolumn{4}{|l|}{ Educational level } \\
\hline High school graduate or lower & $17,649(29.1)$ & $8,209(24.9)$ & $9,440(34.2)$ \\
\hline Some college & $21,293(35.2)$ & $11,032(33.5)$ & $10,261(37.2)$ \\
\hline College graduate & $10,267(17.0)$ & $6,326(19.2)$ & $3,941(14.3)$ \\
\hline Postgraduate & $11,351(18.7)$ & $7,395(22.4)$ & $3,956(14.3)$ \\
\hline \multicolumn{4}{|l|}{ Annual family income } \\
\hline$<$ USD 50,000 & $30,195(59.6)$ & $15,057(53.0)$ & $15,138(68.2)$ \\
\hline USD 50,000-99,000 & $15,666(31.0)$ & $9,961(35.1)$ & $5,705(25.7)$ \\
\hline$\geq$ USD 100,000 & $4,743(9.4)$ & $3,382(11.9)$ & $1,361(6.1)$ \\
\hline \multicolumn{4}{|l|}{ Marital status } \\
\hline Married/cohabiting & $48,162(79.5)$ & $28,511(86.5)$ & $19,651(71.2)$ \\
\hline Single & $12,410(20.5)$ & $4,459(13.5)$ & $7,951(28.8)$ \\
\hline \multicolumn{4}{|l|}{ Occupational status } \\
\hline Employed & $26,326(43.6)$ & $15,943(48.5)$ & $10,383(37.7)$ \\
\hline Homeworker/unemployed/retired & $31,651(52.4)$ & $15,673(47.6)$ & $15,978(58.1)$ \\
\hline Extended sick leave/disabled & $1,124(1.8)$ & $596(1.8)$ & $528(1.9)$ \\
\hline Others & $1,327(2.2)$ & $692(2.1)$ & $635(2.3)$ \\
\hline \multicolumn{4}{|l|}{ Arm } \\
\hline Screening & $31,328(51.6)$ & $17,327(52.5)$ & $14,001(50.6)$ \\
\hline Usual care & $2,849(48.4)$ & $15,699(47.5)$ & $13,641(49.4)$ \\
\hline \multicolumn{4}{|l|}{ Years from study entry to follow-up } \\
\hline$<10$ years & $40,128(66.1)$ & $19,922(60.3)$ & $20,206(73.1)$ \\
\hline$\geq 10$ years & $20,540(33.9)$ & $13,104(39.7)$ & $7,436(26.9)$ \\
\hline \multicolumn{4}{|l|}{ Family history of cancer } \\
\hline No & $26,601(44.0)$ & $15,570(47.3)$ & $11,031(40.0)$ \\
\hline Yes & $33,913(56.0)$ & $17,382(52.7)$ & $16,531(60.0)$ \\
\hline \multicolumn{4}{|l|}{ Personal history of chronic diseases } \\
\hline Arthritis & $29,600(48.8)$ & $12,948(43.7)$ & $16,652(56.3)$ \\
\hline Diabetes & $10,510(17.3)$ & $6,229(59.3)$ & $4,281(40.7)$ \\
\hline Emphysema & $2,003(3.3)$ & $1,210(60.4)$ & $793(39.6)$ \\
\hline Heart attack & $6,076(10.0)$ & $4,656(76.6)$ & $1,420(23.4)$ \\
\hline Hypertension & $33,667(55.5)$ & $17,660(52.5)$ & $16,007(47.5)$ \\
\hline Osteoporosis & $6,837(11.3)$ & $928(13.6)$ & $5,909(86.4)$ \\
\hline Stroke & $3,409(5.6)$ & $2,043(59.9)$ & $1,366(40.1)$ \\
\hline \multicolumn{4}{|c|}{ Diagnosis of cancer during the study period } \\
\hline No & $49,709(83.5)$ & $25,903(80.3)$ & $23,806(87.3)$ \\
\hline Yes & $9,801(16.5)$ & $6,340(19.7)$ & $3,461(12.7)$ \\
\hline \multicolumn{4}{|l|}{ Baseline smoking status } \\
\hline Never smoker & $28,285(46.6)$ & $12,346(37.4)$ & $15,939(57.7)$ \\
\hline Current smoker & $27,851(45.9)$ & $18,017(54.6)$ & $9,834(35.6)$ \\
\hline Former smoker & $4,523(7.5)$ & $2,655(8.0)$ & $1,868(6.7)$ \\
\hline
\end{tabular}


Table 1 (continued)

\begin{tabular}{|c|c|c|c|}
\hline Characteristics & $\begin{array}{l}\text { Total } \\
(n=60,668)\end{array}$ & $\begin{array}{l}\text { Males } \\
(n=33,026)\end{array}$ & $\begin{array}{l}\text { Females } \\
(n=27,642)\end{array}$ \\
\hline \multicolumn{4}{|l|}{ Pack-years } \\
\hline 0 & $28,285(47.1)$ & $12,346(37.9)$ & $15,939(58.2)$ \\
\hline $1-10$ & $5,816(9.7)$ & $3,078(9.4)$ & $2,738(10.0)$ \\
\hline $11-50$ & $18,753(31.3)$ & $11,902(36.5)$ & $6,851(25.0)$ \\
\hline $51-100$ & $6,091(10.1)$ & $4,422(13.6)$ & $1,669(6.1)$ \\
\hline$\geq 101$ & $1,055(1.8)$ & $863(2.6)$ & $192(0.7)$ \\
\hline \multicolumn{4}{|l|}{ Change in smoking status } \\
\hline Consistent non-smoker & $25,805(45.5)$ & $10,856(35.3)$ & $14,949(57.5)$ \\
\hline Consistent former smoker & $25,939(45.7)$ & $16,947(55.1)$ & $8,992(34.6)$ \\
\hline New quitter & $1,577(2.8)$ & $960(3.1)$ & $617(2.4)$ \\
\hline Relapsed smoker & $860(1.5)$ & $533(1.7)$ & $327(1.3)$ \\
\hline Consistent current smoker & $2,577(4.5)$ & $1,488(4.8)$ & $1,089(4.2)$ \\
\hline \multicolumn{4}{|l|}{ Drinking status } \\
\hline Never & $4,917(8.1)$ & $1,639(5.0)$ & $3,278(11.8)$ \\
\hline Former drinker & $7,846(12.9)$ & $4,092(12.4)$ & $3,754(13.6)$ \\
\hline Current drinker & $39,139(64.5)$ & $22,510(68.1)$ & $16,629(60.2)$ \\
\hline Missing & $8,766(14.5)$ & $4,785(14.5)$ & $3,981(14.4)$ \\
\hline \multicolumn{4}{|c|}{ Activity level compared with 10 years ago } \\
\hline About the same & $21,550(36.0)$ & $12,604(38.8)$ & $8,964(32.8)$ \\
\hline Less active & $33,382(55.8)$ & $17,339(53.3)$ & $16,043(58.8)$ \\
\hline More active & $4,884(8.2)$ & $2,581(7.9)$ & $2,303(8.4)$ \\
\hline \multicolumn{4}{|l|}{ BMI at study entry $\left(\mathrm{kg} / \mathrm{m}^{2}\right)$} \\
\hline Overweight (25-29.9) & $39,595(65.3)$ & $23,013(69.7)$ & $16,582(60.0)$ \\
\hline Obesity class I (30-34.9) & $15,182(25.0)$ & $7,954(24.1)$ & $7,228(26.1)$ \\
\hline Obesity class II/III ( $\geq 35$ ) & $5,891(9.7)$ & $2,059(6.2)$ & $3,832(13.9)$ \\
\hline \multicolumn{4}{|l|}{ BMI at 20 years old $\left(\mathrm{kg} / \mathrm{m}^{2}\right)$} \\
\hline Underweight $(<18.5)$ & $2,798(4.6)$ & $945(2.9)$ & $1,853(6.7)$ \\
\hline Normal weight (18.5-24.9) & $44,799(74.2)$ & $22,268(67.7)$ & $22,531(81.9)$ \\
\hline Overweight (25-29.9) & $11,281(18.7)$ & $8,797(26.7)$ & $2,484(9.0)$ \\
\hline Obesity $(\geq 30)$ & $1,512(2.5)$ & $875(2.7)$ & $637(2.3)$ \\
\hline \multicolumn{4}{|l|}{ BMI at 50 years old $\left(\mathrm{kg} / \mathrm{m}^{2}\right)$} \\
\hline Underweight $(<18.5)$ & $40(0.1)$ & $18(0.1)$ & $22(0.1)$ \\
\hline Normal weight (18.5-24.9) & $15,034(24.9)$ & $5,406(16.4)$ & $9,628(64.0)$ \\
\hline Overweight (25-29.9) & $33,441(55.3)$ & $21,153(64.2)$ & $12,288(36.7)$ \\
\hline Obesity $(\geq 30)$ & $11,963(19.7)$ & $6,381(19.3)$ & $5,582(20.2)$ \\
\hline Percent weight change, mean (SD) & $-0.55(8.75)$ & $-0.13(7.95)$ & $-1.07(9.59)$ \\
\hline Clinically meaningful weight loss & $16,135(26.6)$ & $7,624(23.1)$ & $8,511(30.8)$ \\
\hline
\end{tabular}

Data are presented as $n(\%)$ unless otherwise stated. The numbers may not sum to the total number of participants due to missing data. BMI, body mass index; SD, standard deviation.

Lifestyle Behaviors. Information on smoking, alcohol drinking and physical activity were collected using the questionnaire. Smoking status (including non-smokers, former smokers, and current smokers) was surveyed at both study entry and follow-up. Changes in smoking status from study entry to follow-up were categorized into 5 groups: consistent non-smokers (participants who reported no smoking both at study entry and follow-up), consistent former smokers (participants who were former smokers both at study entry and follow-up), new quitters (participants who were current smokers at study entry but former smokers at follow-up), relapsed smokers (participants who were former smokers at study entry but current smokers at follow-up), and consistent current smokers (participants who were current smokers both at study entry and follow-up). Pack-years were calculated by the number of cigarette packs smoked per day $\times$ years smoked. Alcohol drinking was categorized into never, former, and current drinkers. Physical activity level compared to 10 years ago was surveyed at follow-up, and categorized into 3 groups: about the same level compared to 10 years ago, less active compared to 10 years ago, and more active compared to 10 years ago.

BMI. Participants' body weight at 20 years old, 50 years old, study entry, and follow-up were self-reported. The self-reported 


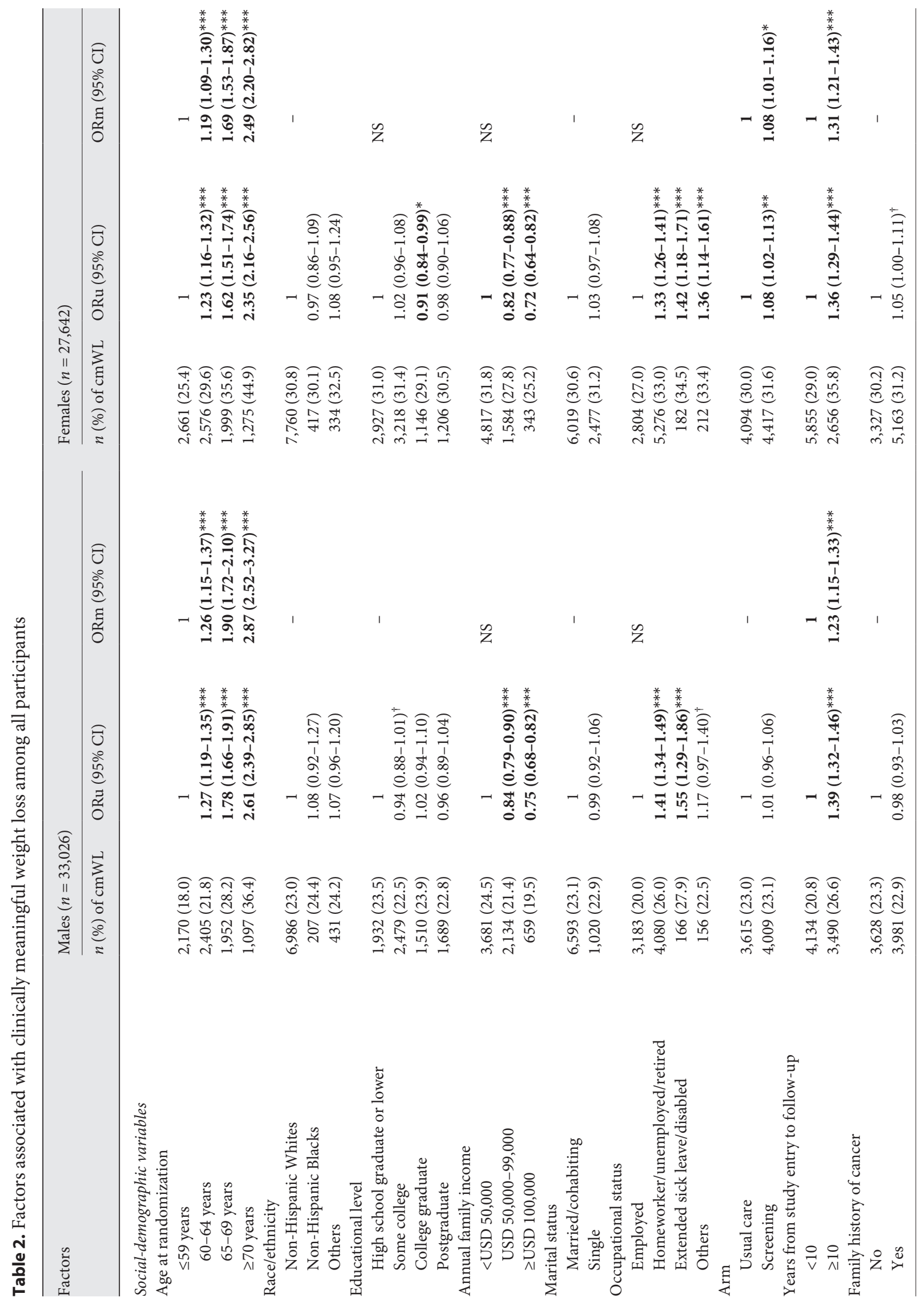




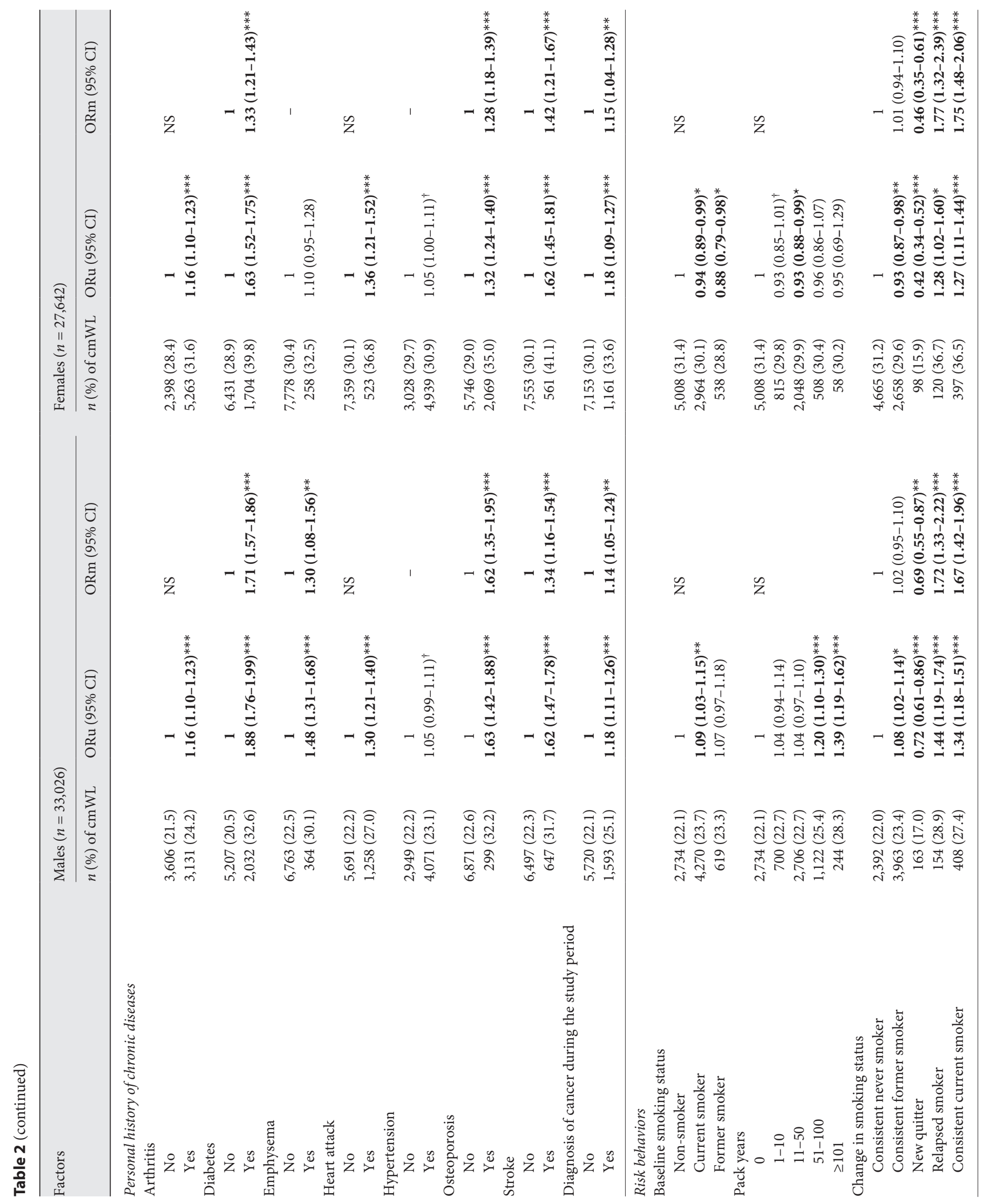




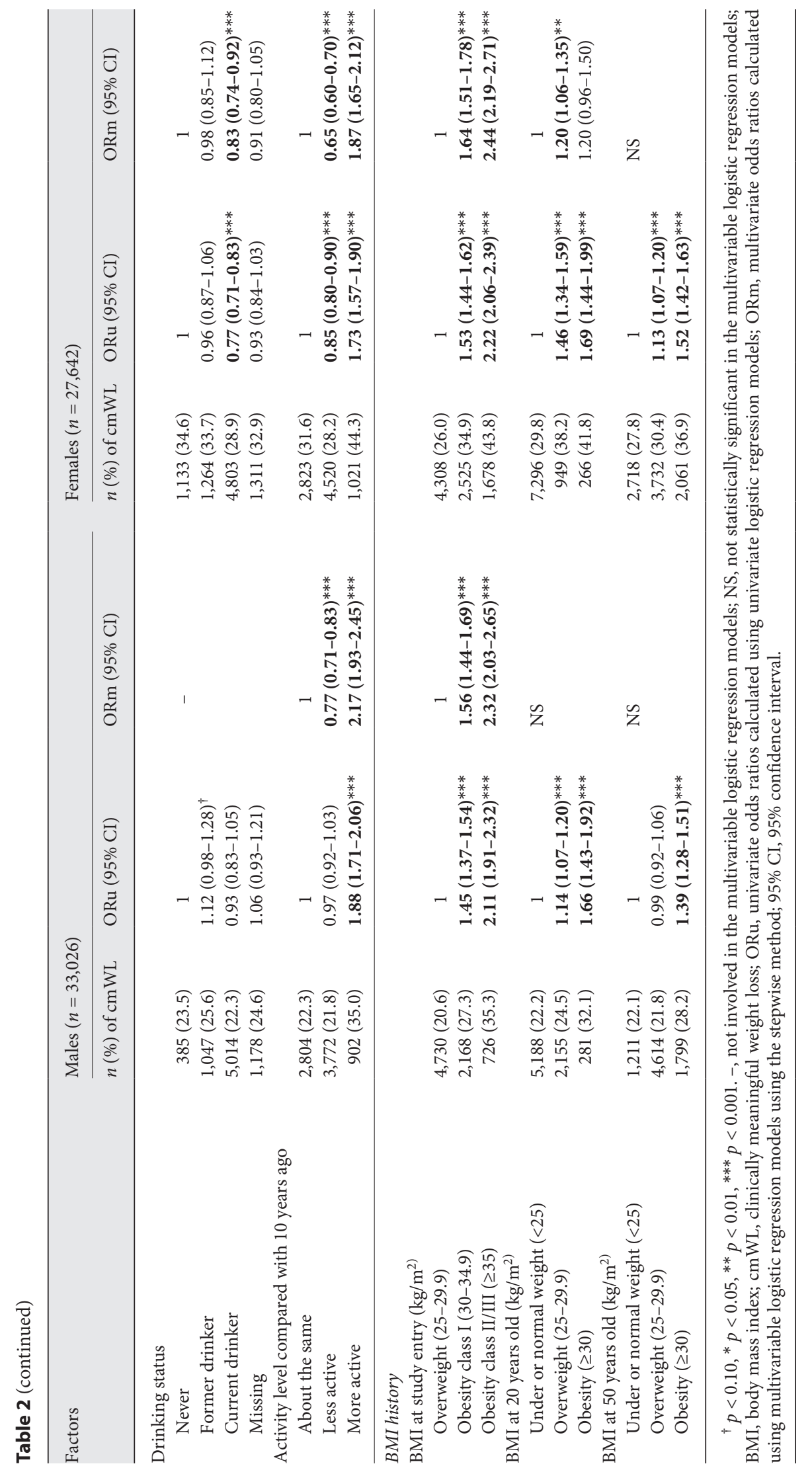


height at study entry was used for BMI calculation. BMI was calculated as weight $(\mathrm{kg})$ divided by the squared of the height $(\mathrm{m})$. Underweight $\left(<18.5 \mathrm{~kg} / \mathrm{m}^{2}\right)$, normal weight $\left(18.5-24.9 \mathrm{~kg} / \mathrm{m}^{2}\right)$, overweight $\left(25.0-29.9 \mathrm{~kg} / \mathrm{m}^{2}\right)$, obesity class I $\left(30-34.9 \mathrm{~kg} / \mathrm{m}^{2}\right)$, and obesity class II combined with class III $\left(35 \mathrm{~kg} / \mathrm{m}^{2}\right.$ or greater) were defined based on the World Health Organization guideline.

Statistical Analyses

The cmWL ( $1=$ yes, $0=$ no) was defined as a weight loss of $\geq 5 \%$ from the date of study entry until follow-up. Differences in potential factors related to $\mathrm{cmWL}$ were compared using the Student $t$ test for continuous variables or $\chi^{2}$ tests for categorical variables. Univariate odds ratios along with $95 \%$ confidence intervals (95\% Cis) of potential factors associated with $\mathrm{cmWL}$ were firstly derived. Predictors associated with $\mathrm{cmWL}$ in univariate analyses at $p<0.05$ level were included in multivariable logistic regression models for risk factors selection using the stepwise method. Sensitivity analyses were then conducted among the participants who had no history of chronic diseases, including arthritis, diabetes, emphysema, heart attack, hypertension, osteoporosis, stroke, and cancer.

All analyses were performed using the SAS software version 9.4 (SAS Institute Inc., Cary, NC, USA). All $p$ values were based on two-sided tests and were considered statistically significant at $p<$ 0.05 .

\section{Results}

\section{Participants' Characteristics}

Among the 60,668 participants, majority of the participants were non-Hispanic whites $(91.7 \%)$ and were married/cohabiting (79.5\%). Around $45.9 \%$ of the participants were current smokers at study entry, and $2.8 \%$ of the current smokers at study entry had quit smoking at follow-up. More than $8 \%$ of the participants had more physical activity compared to 10 years ago, and $55.8 \%$ reported less physical activity compared to 10 years ago (Table 1). The differences in all sample characteristics between males and females were statistically significant.

During a median follow-up of 9.13 years, $26.6 \%$ of the participants achieved $\mathrm{cmWL}$, and the prevalence of cmWL among females was significantly higher than that among males (30.8\% in females vs. $23.1 \%$ in males, $p<$ 0.001 ; Table 1).

Factors Associated with cmWL among All Participants Multivariable logistic regression models showed that participants who were older age (ORm [multivariable odds ratio] range 1.26-2.87 for males; $1.19-2.49$ for females), had an obese status at study entry (ORm range 1.56-2.32 for males; $1.64-2.44$ for females), were more physically active compared to 10 years ago (ORm: 2.17 for males, 1.87 for females), were relapsed smokers (ORm: 1.72 for males; 1.77 for females) or consistent current smokers (ORm: 1.67 for males; 1.75 for females), had a personal history of diabetes (ORm: 1.71 for males, 1.33 for females), osteoporosis (ORm: 1.62 for male, 1.28 for females), and stroke (ORm: 1.34 for males; 1.42 for females), had a cancer diagnosis during the study period (ORm: 1.14 for male; 1.15 for female), and were followed for more than 10 years (ORm: 1.23 for males; 1.31 for females) were more likely to achieve $\mathrm{cmWL}$, in both males and females (Table 2). Moreover, new smoking quitters (ORm: 0.69 for males; 0.46 for females) and participants who had less physical activity compared to 10 years ago (ORm: 0.77 for males; 0.65 for females) were less likely to achieve $\mathrm{cmWL}$ in both males and females.

Specifically, for males, those with a personal history of emphysema were more likely to achieve cmWL (ORm: $1.30,95 \%$ CI 1.08-1.56; $p<0.01)$. For females, those who were overweight at 20 years old (ORm: 1.20, 95\% CI 1.06$1.35 ; p<0.01)$, and were in the cancer screening arm (OR $1.08,95 \%$ CI $1.01-1.16 ; p<0.05)$ were more likely to achieve cmWL. However, current female drinkers were less likely to achieve cmWL (ORm: 0.83 , 95\% CI $0.74-$ 0.92; $p<0.001$; Table 2).

\section{Factors Associated with cmWL among Participants} without Chronic Diseases

Sensitivity analyses were conducted among the participants who had no history of chronic diseases, including arthritis, diabetes, emphysema, heart attack, hypertension, osteoporosis, stroke, and cancer. Our findings showed that participants who achieved $\mathrm{cmWL}$ were more likely to be older (ORm: 2.49-3.20 for males; 1.63-2.75 for females), more physically active compared to 10 years ago (ORm: 1.99 for males; 1.36 for females), and had an obese status at study entry (obesity class I: ORm $=1.91$ for males and 1.56 for females; obesity class II/III: ORm $=3.41$ for males and 2.86 for females), in both males and females. New smoking quitters (ORm: 0.23 for males, 0.20 for females) and those who were less physically active compared to 10 years ago (ORm: 0.81 for males; 0.53 for females) had a lower probability of achieving cmWL (Table 3).

For male participants, the probability of $\mathrm{cmWL}$ was significantly higher among those who were relapsed smokers (ORm: 3.13, 95\% CI 1.77-5.53), consistent current smokers (ORm: 1.70, 95\% CI 1.18-2.46), those on extended sick leave or disabled (ORm: 3.90, 95\% CI 1.3811.01), but lower in those who reported higher annual family income (ORm: $0.81,95 \%$ CI $0.66-0.99$ for USD 50,000-99,000; ORm: $0.68,95 \%$ CI $0.51-0.90$ for $\geq$ USD $100,000)$. However, there were no female-specific factors that were associated with $\mathrm{cmWL}$ (Table 3 ). 


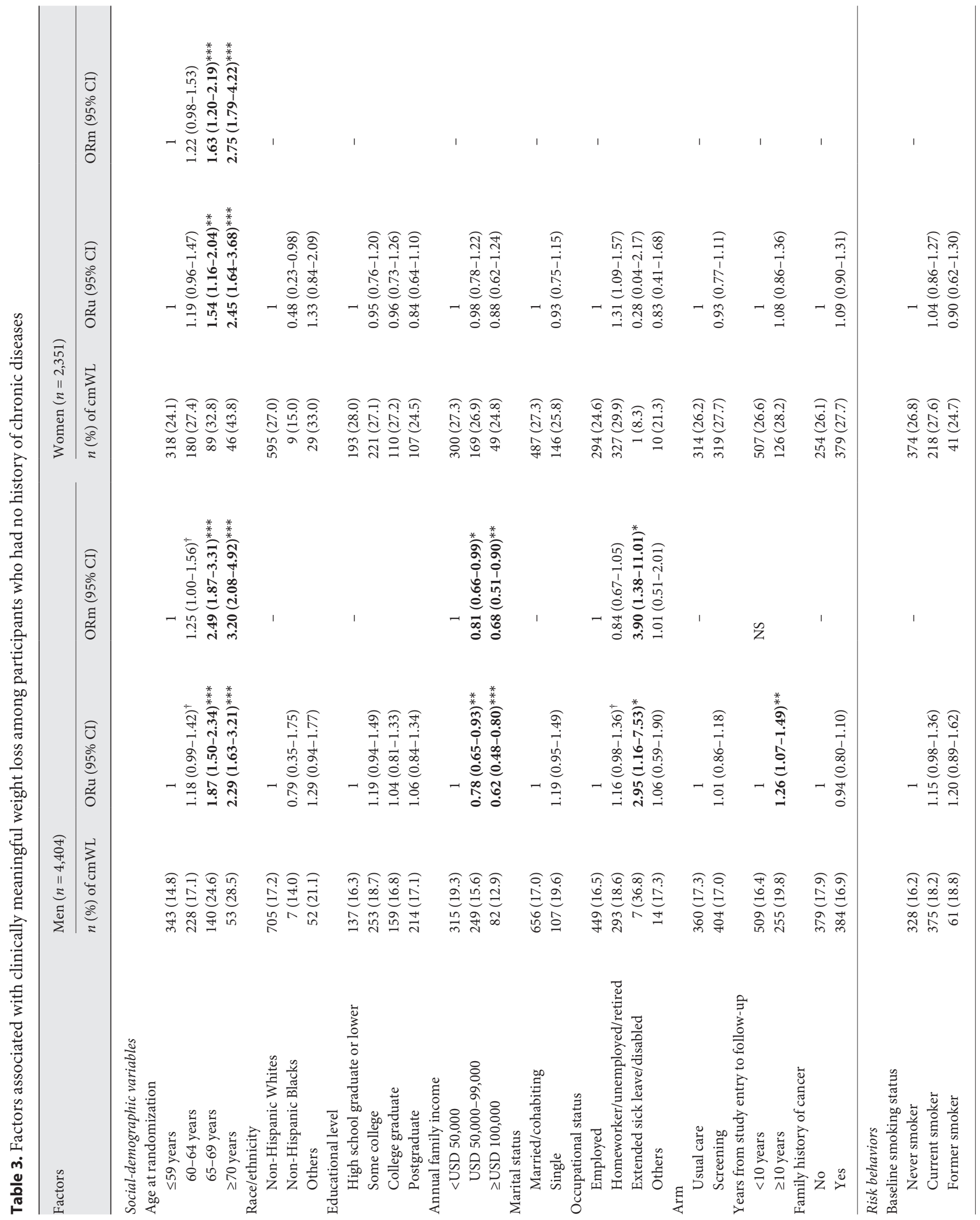




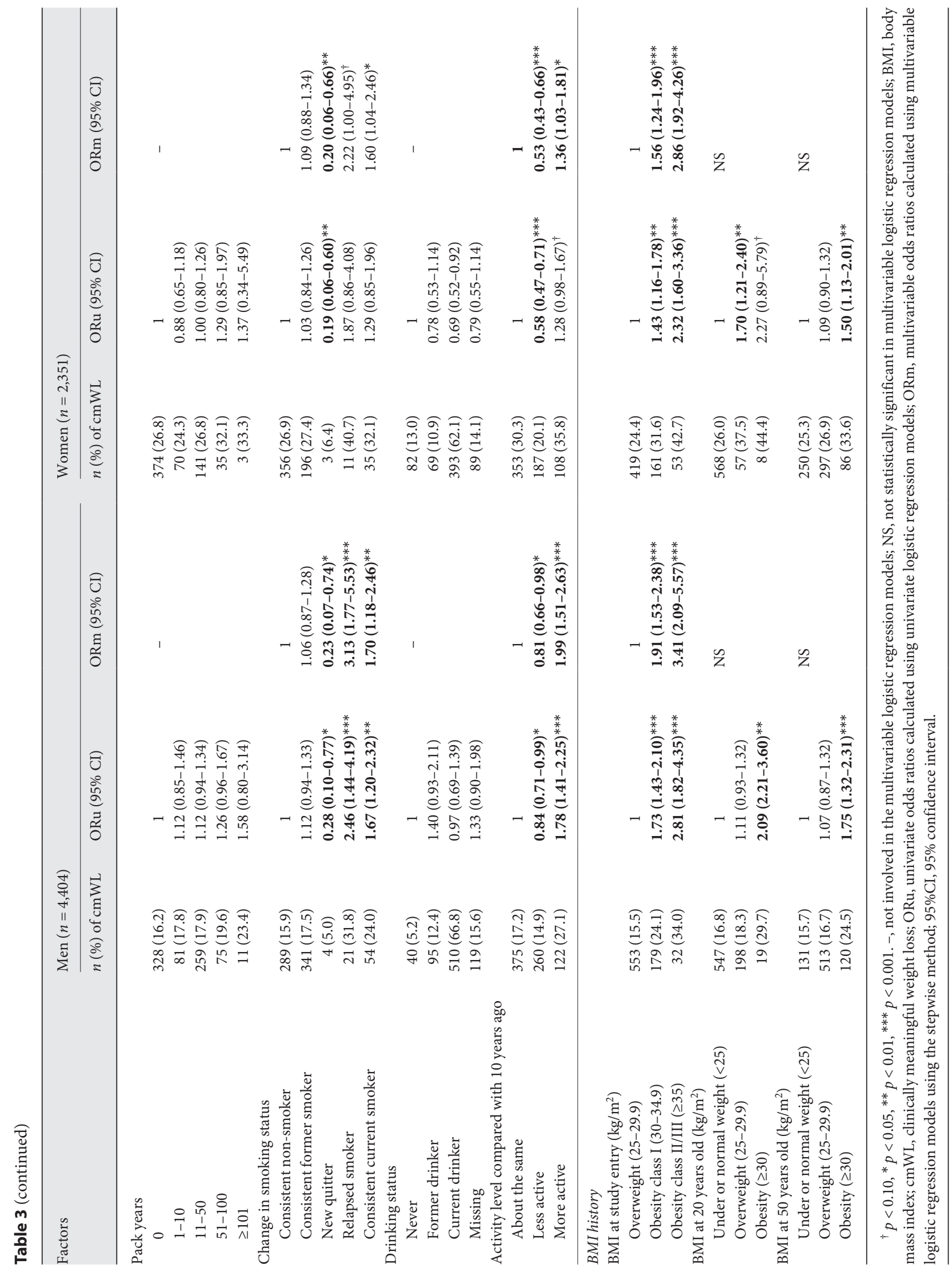




\section{Discussion}

Using the data from the PLCO study, we systematically evaluated the potential factors associated with cmWL in males and females, separately. Our findings showed that older age, more physical activity, and obese status at study entry were positive factors of achieving $\mathrm{cmWL}$, while quitting smoking was a negative factor of $\mathrm{cmWL}$ in both males and females. Consistent current smoking, relapsed smoking, and extended period of sick leave/being disabled were male-specific positive factors of $\mathrm{cmWL}$, but high annual family income was a male-specific negative factor of $\mathrm{cmWL}$.

We observed that females had a higher prevalence of cmWL than males, which was consistent with a previous study [16]. Women were more likely to perceive themselves as overweight or obese status than men [30-33]. This disparity might be partially attributable to different attitudes and perceptions of body weight between males and females due to social pressure. Women generally internalize a thin ideal and usually felt unsatisfied when comparing themselves to slender female images. In contrast, the ideal and widely acceptable male body type was to be muscular rather than skinny [34], but men did not hold a strong value of shaping themselves into an ideal body size as compared to women [35]. Overall, the misperception of males in body weight was associated with their less attempts for weight control and lower level of physical activity, which consequently resulted in a lower prevalence of critical weight loss [33].

Consistent with previous studies, participants who were older, obese and more physically active had a higher probability of achieving cmWL $[14,16,36]$. Besides, relapsed smokers or consistent current smokers were more likely to reach $\mathrm{cmWL}$, whereas new smoking quitters were less likely to reach cmWL [37]. Participants with a history of chronic diseases (i.e., diabetes, osteoporosis, stroke, and newly diagnosed cancers) had a higher prevalence of cmWL [38-40]. Sensitivity analyses showed that participants who were older, more physically active, and with an obese status at study entry were more likely to achieve cmWL in both genders. New smoking quitters had a lower rate of $\mathrm{cmWL}$ among both males and females. However, we found that only males who were relapsed smokers or consistent current smokers were more likely to reach $\mathrm{cmWL}$. The association between smoking behavior and weight loss seems to be complicated. A previous study reported that smoking was positively associated with weight loss, while smoking cessation was related to weight gain [37], which was similar to our findings that new smoking quitters were less likely to achieve cmWL. Another study reported that the number of cigarettes per day was associated with long-term weight gain following smoking cessation [41]. However, a recent study reported no difference in long-term weight loss between never smokers, former smokers, and current smokers [42]. It was intriguing to find that females in the cancer screening arm had a higher probability of achieving cmWL than those in the usual care arm. The results indicated that adults who were involved in the screening arm may intentionally control their body weight as a way to reduce the risk of morbidity and mortality. This indicates that cancer screening could serve as a potential "teachable moment" for obesity intervention [43], as the cancer screening sites could be easily applied to conduct body weight reduction intervention. However, the extent to which screening results could alarm individuals to amend their risk behaviors/factors in order to control body weight is still unknown and needs future research.

The present study investigated the predictors of $\mathrm{cmWL}$ among midlife to older adults and their gender differences using a large-scale prospective cohort study. The study design and data quality were reliable considering that the data in the present study was from a randomized trial. Our findings have implications for future interventional research aiming at the maintenance of long-term weight loss, given that an increase in initial weight loss was associated with larger long-term weight loss [44]. However, several limitations might exist in the present study. First, there might be recall bias due to self-reported body weight, and there may have been exaggeration of weight loss due to social desirability. Second, other potentially important factors associated with weight loss (e.g., history of medical interventions, eating behaviors and other lifestyle modification, dietary intake, psychological history, social environments) were not analyzed in this study due to the restriction of information collected in the PLCO study. Third, measurements of body weight were performed only twice, and could not accurately represent the long-term weight status. Fourth, the duration of being overweight/obese may be an important factor influencing weight control, and the intention to control weight among adults with a long-term duration of overweight/obesity is obviously different from those with a short-tern duration of overweight/obesity. Fifth, there might exist unintentional weight loss in our sample which might bias our findings, although our sensitivity analyses by excluding participants with chronic diseases demonstrated similar results. Sixth, there might be third variables which mediate/moderate (e.g., attitude toward weight control) the association between predictors in our study and 
$\mathrm{cmWL}$ across genders. Moreover, due to the nature of secondary analysis, it is less likely to make any causal inferences regarding the association between analyzed factors and $\mathrm{cmWL}$.

\section{Conclusions}

Our findings suggested that consistent current smoking, relapsed smoking, and extended duration of sick leave/being disabled were male-specific positive factors associated with $\mathrm{cmWL}$, while high annual family income was a malespecific negative factor associated with $\mathrm{cmWL}$. Additionally, older age, more physical activity, and obese status at study entry were positive factors of $\mathrm{cmWL}$, while quitting smoking was a negative factor of $\mathrm{cmWL}$, in both males and females. Therefore, to facilitate long-term $\mathrm{cmWL}$, factors including age, physical activity, obesity status, family income, smoking status need to be separately considered in males and females. Moreover, further well-designed prospective studies are warranted to evaluate the gender differences in other potential factors associated with weight loss, such as a history of medication use, duration of overweight/ obesity, eating behavior, and diet status. Also, well-designed randomized controlled trials involving different weight loss strategies are warranted to confirm our findings.

\section{Acknowledgment}

The authors thank the National Cancer Institute (NCI) for access to the data of the Prostate, Lung, Colorectal and Ovarian (PLCO) Cancer Screening Trial. The statements contained herein are solely those of the authors and do not represent or imply concurrence or endorsement by NCI. The authors would also like to appreciate Dr. Seeruttun Sharvesh Raj, an editor of Cancer Communications in Sun Yat-sen University Cancer Center, for the language editing of the manuscript.

\section{Statement of Ethics}

This study is a secondary analysis for the data from the PLCO program sponsored by National Cancer Institute, and the clinical trial numbers were NCT00002540 (Prostate), NCT01696968 (Lung), NCT01696981 (Colorectal), NCT01696994 (Ovarian). The PLCO study was reviewed and approved by the Institutional Review Board of the National Cancer Institute (NCI) and the ten centers, and all participants provided written informed consent. The IRB protocol number of the PLCO program is OH97-C-N041. The present study (approved No. by NCI: PLCO-295) was approved by National Cancer Institute in 2017, and the data extracts were di-identified prior to their release to authors. This study was conducted in accordance with the ethical standards of the institutional and/or national research committee and with the $1964 \mathrm{Hel}-$ sinki Declaration and its later amendments or comparable ethical standards.

\section{Conflict of Interest Statement}

The authors declare that they have no competing interests.

\section{Funding Sources}

There are no funding sources to declare.

\section{Author Contributions}

J.-B.L., J.-D.L., and X.Z. conceived and designed this study; J.B.L. and X.Z. did the statistical analyses. J.-B.L., Z.-Y.Q., and X.Z. drafted the manuscript. J.-B.L., Z.-Y.Q., Z.L., Q.Z., L.-F.F., J.-D.L., and X.Z. revised and critically reviewed the manuscript. All authors read and approved the final version of the manuscript.

\section{References}

1 Sung H, Siegel RL, Torre LA, Pearson-Stuttard J, Islami F, Fedewa SA, et al. Global patterns in excess body weight and the associated cancer burden. CA Cancer J Clin. 2019 Mar; 69(2):88-112.

2 Wormser D, Kaptoge S, Di Angelantonio E, Wood AM, Pennells L, Thompson A, et al.; Emerging Risk Factors Collaboration. Separate and combined associations of body-mass index and abdominal adiposity with cardiovascular disease: collaborative analysis of 58 prospective studies. Lancet. 2011 Mar; 377(9771):1085-95.
3 Singh GM, Danaei G, Farzadfar F, Stevens GA, Woodward M, Wormser D, et al.; Global Burden of Metabolic Risk Factors of Chronic Diseases Collaborating Group; Asia-Pacific Cohort Studies Collaboration (APCSC); Diabetes Epidemiology: Collaborative analysis of Diagnostic criteria in Europe (DECODE); Emerging Risk Factor Collaboration (ERFC); Prospective Studies Collaboration (PSC). The age-specific quantitative effects of metabolic risk factors on cardiovascular diseases and diabetes: a pooled analysis. PLoS One. 2013 Jul; 8(7):e65174.
4 Jiang L, Rong J, Wang Y, Hu F, Bao C, Li X, et al. The relationship between body mass index and hip osteoarthritis: a systematic review and meta-analysis. Joint Bone Spine. 2011 Mar;78(2):150-5.

5 Lauby-Secretan B, Scoccianti C, Loomis D, Grosse Y, Bianchini F, Straif K; International Agency for Research on Cancer Handbook Working Group. Body Fatness and CancerViewpoint of the IARC Working Group. N Engl J Med. 2016 Aug;375(8):794-8. 
6 Yao W, Meng Y, Lu M, Fan W, Huang J, Li J, et al. Impact of type 2 diabetes mellitus on short-term and long-term outcomes of patients with esophageal squamous cell cancer undergoing resection: a propensity score analysis. Cancer Commun (Lond). 2018 Apr; 38(1):14.

7 Birks S, Peeters A, Backholer K, O’Brien P, Brown W. A systematic review of the impact of weight loss on cancer incidence and mortality. Obes Rev. 2012 Oct;13(10):868-91.

8 Blackburn G. Effect of degree of weight loss on health benefits. Obes Res. 1995 Sep;3(Sup$\mathrm{pl} 2)$ :211s-6s.

9 Fantin F, Giani A, Zoico E, Rossi AP, Mazzali G, Zamboni M. Weight Loss and Hypertension in Obese Subjects. Nutrients. 2019 Jul; 11(7):E1667.

10 Himbert C, Thompson H, Ulrich CM. Effects of Intentional Weight Loss on Markers of Oxidative Stress, DNA Repair and Telomere Length - a Systematic Review. Obes Facts. 2017;10(6):648-65.

11 Cordier D, Gerber M, Brand S. Effects of two types of exercise training on psychological well-being, sleep, quality of life and physical fitness in patients with high-grade glioma (WHO III and IV): study protocol for a randomized controlled trial. Cancer Commun (Lond). 2019 Aug;39(1):46.

12 Nicklas JM, Huskey KW, Davis RB, Wee CC. Successful weight loss among obese U.S. adults. Am J Prev Med. 2012 May;42(5):481-

13 Melanson EL, Keadle SK, Donnelly JE, Braun B, King NA. Resistance to exercise-induced weight loss: compensatory behavioral adaptations. Med Sci Sports Exerc. 2013 Aug;45(8): $1600-9$.

14 Teixeira PJ, Going SB, Sardinha LB, Lohman TG. A review of psychosocial pre-treatment predictors of weight control. Obes Rev. 2005 Feb;6(1):43-65.

15 Franz MJ, VanWormer JJ, Crain AL, Boucher JL, Histon T, Caplan W, et al. Weight-loss outcomes: a systematic review and meta-analysis of weight-loss clinical trials with a minimum 1-year follow-up. J Am Diet Assoc. 2007 Oct; 107(10):1755-67.

16 Jackson SE, Beeken RJ, Wardle J. Predictors of weight loss in obese older adults: findings from the USA and the UK. Obes Facts. 2014; $7(2): 102-10$.

17 Jiandani D, Wharton S, Rotondi MA, Ardern CI, Kuk JL. Predictors of early attrition and successful weight loss in patients attending an obesity management program. BMC Obes. 2016 Mar;3(1):14.

18 Gasteyger C, Christensen R, Larsen TM, Vercruysse F, Toubro S, Astrup A. Center-size as a predictor of weight-loss outcome in multicenter trials including a low-calorie diet. Obesity (Silver Spring). 2010 Nov; 18(11):2160-4.

19 Kimokoti RW, Newby PK, Gona P, Zhu L, Jasuja GK, Pencina MJ, et al. Diet quality, physical activity, smoking status, and weight fluctuation are associated with weight change in women and men. J Nutr. $2010 \mathrm{Jul}$;40(7): 1287-93.

20 Jakicic JM, Tate DF, Lang W, Davis KK, Polzien K, Neiberg RH, et al. Objective physical activity and weight loss in adults: the step-up randomized clinical trial. Obesity (Silver Spring). 2014 Nov;22(11):2284-92.

21 Feng RM, Zong YN, Cao SM, Xu RH. Current cancer situation in China: good or bad news from the 2018 Global Cancer Statistics? Cancer Commun (Lond). 2019 Apr;39(1):22.

22 Williams RL, Wood LG, Collins CE, Callister R. Effectiveness of weight loss interventionsis there a difference between men and women: a systematic review. Obes Rev. 2015 Feb; 16(2):171-86

23 Morgan PJ, Hollis JL, Young MD, Collins CE, Teixeira PJ. Workday Sitting Time and Marital Status: Novel Pretreatment Predictors of Weight Loss in Overweight and Obese Men. Am J Men Health. 2018 Sep; 12(5):1431-8.

24 Kyryliuk R, Baruth M, Wilcox S. Predictors of Weight Loss for African-American Women in the Faith, Activity, and Nutrition (FAN) Study. J Phys Act Health. 2015 May;12(5): 659-65.

25 Ard JD, Carson TL, Shikany JM, Li Y, Hardy CM, Robinson JC, et al. Weight loss and improved metabolic outcomes amongst rural African American women in the Deep South: six-month outcomes from a communitybased randomized trial. J Intern Med. 2017 Jul;282(1):102-13.

26 Ramel A, Arnarson A, Parra D, Kiely M, Bandarra NM, Martinéz JA, et al. Gender difference in the prediction of weight loss by leptin among overweight adults. Ann Nutr Metab. 2010;56(3):190-7.

27 Wang P, Holst C, Wodzig WK, Andersen MR, Astrup A, van Baak MA, et al.; Diogenes consortium. Circulating ACE is a predictor of weight loss maintenance not only in overweight and obese women, but also in men. Int J Obes. 2012 Dec;36(12):1545-51.

28 Jerome GJ, Myers VH, Young DR, MatthewsEwald MR, Coughlin JW, Wingo BC, et al. Psychosocial predictors of weight loss by race and sex. Clin Obes. 2015 Dec;5(6):342-8.

29 Gohagan JK, Prorok PC, Hayes RB, Kramer BS; Prostate, Lung, Colorectal and Ovarian Cancer Screening Trial Project Team. The Prostate, Lung, Colorectal and Ovarian (PLCO) Cancer Screening Trial of the National Cancer Institute: history, organization, and status. Control Clin Trials. 2000 Dec;21(6 Suppl):251S-72S

30 Millstein RA, Carlson SA, Fulton JE, Galuska DA, Zhang J, Blanck HM, et al. Relationships between body size satisfaction and weight control practices among US adults. Medscape J Med. 2008 May;10(5):119.

31 Lemon SC, Rosal MC, Zapka J, Borg A, Andersen V. Contributions of weight perceptions to weight loss attempts: differences by body mass index and gender. Body Image. 2009 Mar;6(2):90-6.
32 Tsai SA, Lv N, Xiao L, Ma J. Gender Differences in Weight-Related Attitudes and Behaviors Among Overweight and Obese Adults in the United States. Am J Men Health. 2016 Sep;10(5):389-98.

33 Duncan DT, Wolin KY, Scharoun-Lee M, Ding EL, Warner ET, Bennett GG. Does perception equal reality? Weight misperception in relation to weight-related attitudes and behaviors among overweight and obese US adults. Int J Behav Nutr Phys Act. 2011 Mar; 8(1):20.

34 Christensen VT. Gendered perceptions of own and partner weight-level. Health (London). 2012 Jul;16(4):382-99.

35 Brown PJ, Konner M. An anthropological perspective on obesity. Ann N Y Acad Sci. 1987;499(1):29-46.

36 Di Pietro L, Dziura J, Blair SN. Estimated change in physical activity level (PAL) and prediction of 5-year weight change in men: the Aerobics Center Longitudinal Study. Int $J$ Obes Relat Metab Disord. 2004 Dec;28(12): 1541-7.

37 Williamson DF, Madans J, Anda RF, Kleinman JC, Giovino GA, Byers T. Smoking cessation and severity of weight gain in a national cohort. N Engl J Med. 1991 Mar;324(11): 739-45.

38 de Fine Olivarius N, Siersma VD, Køster-Rasmussen R, Heitmann BL, Waldorff FB. Weight changes following the diagnosis of type 2 diabetes: the impact of recent and past weight history before diagnosis. results from the Danish Diabetes Care in General Practice (DCGP) study. PLoS One. 2015 Apr; 10(4):e0122219.

39 Jackson SE, Williams K, Steptoe A, Wardle J. The impact of a cancer diagnosis on weight change: findings from prospective, population-based cohorts in the UK and the US. BMC Cancer. 2014 Dec;14(1):926.

40 Sabaka P, Dukat A, Gajdosik J, Bendzala M, Caprnda M, Simko F. The effects of body weight loss and gain on arterial hypertension control: an observational prospective study. Eur J Med Res. 2017 Oct:22(1):43.

41 Veldheer S, Yingst J, Zhu J, Foulds J. Ten-year weight gain in smokers who quit, smokers who continued smoking and never smokers in the United States, NHANES 2003-2012. Int J Obes. 2015 Dec;39(12):1727-32.

42 Murphy CM, Rohsenow DJ, Johnson KC, Wing RR. Smoking and weight loss among smokers with overweight and obesity in Look AHEAD. Health Psychol. 2018 May;37(5): 399-406.

43 Lee AS, Ozakinci G, Leung S, Humphris G, Dale H, Hamlet N. Lifestyle change in the cancer setting using 'the teachable moment': protocol for a proof-of-concept pilot in a urology service. Pilot Feasibility Stud. 2016 Oct;2(1):65.

44 MacLean PS, Wing RR, Davidson T, Epstein L, Goodpaster B, Hall KD, et al. NIH working group report: innovative research to improve maintenance of weight loss. Obesity (Silver Spring). 2015 Jan;23(1):7-15. 